\title{
Mechanical Properties and Micro Morphology of Granite Residual Soil-Based Fly Ash Geopolymer
}

\author{
Yue HUANG ${ }^{\mathrm{a}}$, Jian LIU ${ }^{\mathrm{b}, \mathrm{c}}$, Yuedong WU ${ }^{\mathrm{b}, \mathrm{c}}$ and Yuanmin DUAN ${ }^{\mathrm{b}, \mathrm{c}, 1}$ \\ ${ }^{a}$ Xinjiang University School of Civil Engineering, 1230 Yan'an Road, Tianshan District, \\ Xinjiang, China. \\ ${ }^{\mathrm{b}}$ Key Laboratory of Ministry of Education for Geomechanics and Embankment \\ Engineering, Hohai University, No. 1, Xikang Road, Gulou District, Nanjing, China. \\ ${ }^{c}$ Geotechnical Engineering Research Center of Jiangsu Province, No. 1, Xikang Road, \\ Gulou District, Nanjing, China
}

\begin{abstract}
In order to explore the polymerization mechanism of granite residual soil, geopolymer containing fly ash, various particle groups, granite residual soil and their composites were prepared with different materials. Sodium hydroxide and sodium silicate are used as alkali activators. In this paper, the compressive strength of geopolymer was studied. The mineral composition and microstructure were tested and analyzed by X-ray diffraction and scanning electron microscope. The results show that geopolymerization can only occur in fine particles due to the presence of amorphous aluminosilicate in granite residual soil. The zeolite phase transition of low polymer in fine-grained reaction is beneficial to enhance the integrity of the sample and improve its compressive strength. The addition of fly ash can accelerate the geopolymerization rate and improve the strength of fine geopolymer, but it can inhibit the occurrence of zeolite phase transformation.
\end{abstract}

Keywords. Granite residual soil, fly ash, geopolymer, amorphous material

\section{Introduction}

The accelerating pace of urbanization in China has brought a large amount of residual sludge, especially in Shenzhen. The average annual output of residual sludge from 2017 to 2020 will reach 91.5 million $\mathrm{m}^{3}$ [1]. At the same time, aiming at the problems of high energy consumption and high carbon emission caused by traditional cement production, people began to explore various new cementitious materials. Geopolymer, as an inorganic cementitious material, has been widely studied because it can greatly reduce greenhouse gas emissions [2], and has the characteristics of high compressive strength, high temperature resistance, chemical corrosion resistance and good impermeability. Therefore, in view of the above problems faced by slag and cement, this paper will use slag as raw material to prepare geopolymer, looking for new possibilities to replace cement cementitious materials.

\footnotetext{
${ }^{1}$ Yuanmin Duan, Key Laboratory of Ministry of Education for Geomechanics and Embankment Engineering, Hohai University, No. 1, Xikang Road, Gulou District, Nanjing, China; E-mail: 17356515281@163.com.
} 
Geopolymer is a new kind of cementitious material formed by reaction with alkali with the material containing active aluminate as raw material. At present, the application of geopolymers is mainly about the fixation of harmful substances, the preparation of mortar and concrete. The application of geological polymerization reaction in soil is still a few. The most used pretreatment methods are calcination, such as Pacheco [3], Mingjie M [4] and no geological polymerization of original soil is used. According to Hailiang W [5] and Qingfeng L [6], the soil particles themselves do not participate in geological polymerization reaction, whether they are for large granular soil or for clay.

In this paper, the strength properties of geopolymer prepared from different raw materials were tested by compressive strength test with $\mathrm{NaOH}$ and sodium silicate as activators, and the response law of different particle groups of fly ash and granite residual soil was analyzed. The chemical and microstructure changes of different raw materials before and after reaction were analyzed by X-ray diffraction and scanning electron microscope, and the geological polymerization mechanism of granite residual soil and fly ash was studied.

\section{Experimental Materials and Methods}

\subsection{Microstructure and Chemical Composition of Raw Materials}

The granite residual soil used in the test is from Pingshan District, Shenzhen City, Guangdong Province. The basic physical parameters of the soil sample are shown in table 1. According to the standard for engineering classification of soil (GB/T 50145$2007)$, the test soil was wet screened to obtain fine particles $(\mathrm{D} \leq 0.075 \mathrm{~mm})$, sand particles $(0.075 \mathrm{~mm}<\mathrm{D} \leq 2 \mathrm{~mm})$ and gravel particles $(2 \mathrm{~mm}<\mathrm{D} \leq 20 \mathrm{~mm})$. At the same time, the chemical composition of soil samples was obtained by X-ray diffraction (XRD) and X-ray fluorescence (XRF), and the microstructure was observed by scanning electron microscope (SEM).

The fly ash used in the test is from Henan Yulian power plant. The chemical composition of fly ash was detected by XRD and XRF, and the microstructure of fly ash was observed by SEM.

The alkali activator is composed of $\mathrm{NaOH}$ (purity $97 \%$, white solid) and sodium silicate (modulus 2.43, $\mathrm{SiO} 2$ content $32.35 \%$, Na2O content $13.73 \%$ ). The modulus of $\mathrm{NaOH}$ is $14 \mathrm{M}$. The mass ratio of sodium silicate to $\mathrm{NaOH}$ solution is 2.3 .

\subsection{Test Plan and Preparation Technology}

Control variables are used in the design of the test scheme. The water solid ratio of fly ash control group was 0.28 . On this basis, the water-solid ratio of the experimental group was adjusted through experiments to make each group have similar fluidity (110 $\mathrm{mm} \sim 130 \mathrm{~mm}$ ). The specific test design is shown in table 2 .

The samples were prepared by cement mortar mixer. First, the materials are stirred evenly. Then the geopolymer slurry is poured into the plastic mold, and vibrated. The surface of the sample was covered with plastic film, and it was allowed to stand at room temperature for $24 \mathrm{~h}$. Then the sample was put into a constant temperature and humidity box at $60{ }^{\circ} \mathrm{C}$ and $50 \% \mathrm{RH}$ for curing for $48 \mathrm{~h}$. Finally, under the standard curing conditions, it was cured to the age of $3 \mathrm{~d}, 7 \mathrm{~d}, 14 \mathrm{~d}$ and $28 \mathrm{~d}$ respectively. 


\subsection{Test Method}

The test method for compressive strength of geopolymer test block prepared can refer to test method for strength of cement mortar (GB/T 17671-1999). The chemical composition and changes were obtained by XRD and XRF. The microstructure and structural characteristics were observed by SEM. XRD was carried out by using D8 advance $250 \mathrm{X}$-ray diffractometer (Bruker D8 advance 250). The specific detection conditions are: $\mathrm{Cu}$ target, continuous scanning mode, scanning range: and step size: $0.02^{\circ}$, The scanning speed is $10 \%$ min. The SEM was acquired by SU8010 scanning electron microscope.

Table 1. Physical properties of granite residual soil.

\begin{tabular}{lllllllll}
\hline $\begin{array}{l}\text { Natural } \\
\text { moisture } \\
\text { content } / \%\end{array}$ & $\begin{array}{l}\text { Natural } \\
\text { density } \\
/\left(\mathrm{g} / \mathrm{cm}^{3}\right)\end{array}$ & $\begin{array}{l}\text { Specific Void } \\
\text { gravity ratio }\end{array}$ & $\begin{array}{l}\text { Natural } \\
\text { saturation limit }\end{array} / \%$ & $\begin{array}{l}\text { liquid } \\
/ \%\end{array}$ & $\begin{array}{l}\text { plastic } \\
\text { limit/\% } \%\end{array}$ & $\begin{array}{l}\text { plasticity } \\
\text { index }\end{array}$ & $\begin{array}{l}\text { Natural } \\
\text { moisture } \\
\text { content } / \%\end{array}$ & $\begin{array}{l}\text { Natural } \\
\text { density } \\
/\left(\mathrm{g} / \mathrm{cm}^{3}\right)\end{array}$ \\
\hline 28.4 & 1.88 & 2.64 & 0.80393 .4 & 40.6 & 27.5 & 13.1 & 28.4 & 1.88 \\
\hline
\end{tabular}

Table 2. Mix proportion.

\begin{tabular}{|c|c|c|c|c|c|c|c|c|}
\hline \multirow{2}{*}{$\begin{array}{l}\text { Trail } \\
\text { No }\end{array}$} & \multirow{2}{*}{$\begin{array}{l}\text { Fly } \\
\text { ash/g }\end{array}$} & \multicolumn{3}{|c|}{ Granite residual soil/g } & \multirow[b]{2}{*}{$\mathrm{NaOH} / \mathrm{g}$} & \multirow[b]{2}{*}{$\mathrm{Na}_{2} \mathrm{SiO}_{3} / \mathrm{g}$} & \multirow[b]{2}{*}{$\mathrm{H}_{2} \mathrm{O} / \mathrm{g}$} & \multirow{2}{*}{$\begin{array}{l}\text { Water } \\
\text { solid } \\
\text { ratio }\end{array}$} \\
\hline & & $\begin{array}{l}\text { Fine } \\
\text { particles }\end{array}$ & sand & $\begin{array}{l}\text { Gravel } \\
\text { particle }\end{array}$ & & & & \\
\hline A & 1300 & 0 & 0 & 0 & \multirow{6}{*}{62.27} & \multirow{6}{*}{362.44} & 168.61 & 0.28 \\
\hline B & 0 & 1300 & 0 & 0 & & & 454.61 & 0.5 \\
\hline $\mathrm{C}$ & 0 & 0 & 1300 & 0 & & & 168.61 & 0.28 \\
\hline $\mathrm{D}$ & 0 & 0 & 0 & 1300 & & & 168.61 & 0.28 \\
\hline $\mathrm{E}$ & 0 & 1300 & & & & & 233.61 & 0.38 \\
\hline $\mathrm{F}$ & 650 & 650 & 0 & 0 & & & 233.61 & 0.38 \\
\hline
\end{tabular}

\section{Results and Discussion}

\subsection{Analysis of Compressive Strength of Geopolymer}

Figure 1 shows the compressive strength of each group of samples under the conditions of $7 \mathrm{~d}, 14 \mathrm{~d}$ and $28 \mathrm{~d}$. It can be seen that the compressive strength of fly ash geopolymer A is significantly higher than that of geopolymers prepared from granite residual soil. The geopolymers prepared with granite residual soil as raw materials have low compressive strength. Among them, the fine-grained sample is only $4.7 \mathrm{MPa}$ at 28 $\mathrm{d}$, while the strength of the sample prepared with granite residual soil full-grain soil is lower, which is only $1.33 \mathrm{MPa}$ at $28 \mathrm{~d}$. It can also be inferred from this that in the granite residual soil, only fine particles can participate in the geological polymerization reaction. However, due to the low content of amorphous silicon-aluminum oxide in the fine particles, the strength of the resulting geopolymer sample is not high. In the geopolymer prepared from the composite raw material of fly ash and granite residual soil fine particles, the strength of the sample is higher than that of the granite residual soil geopolymer but lower than that of pure fly ash geopolymer. This is also related to the amorphous silicon aluminum oxide content in the raw material. 


\subsection{XRD Structure Analysis of Geopolymer}

In order to further study the mechanism of the geological polymerization reaction of various substances, the test analyzed the hydration products of fly ash, granite residual soil fine particles and fly ash + fine particle composite raw material geopolymers under different curing ages, and the results are shown in figures $2 \sim 4$.

Figure 2 is the XRD pattern of fly ash geopolymers under different curing ages. The diffraction patterns of the samples before and after the reaction were basically similar without significant difference, and the main crystal phases were quartz and mullite phases. Compared with fly ash raw materials, the original quartz phase and mullite phase peak intensity is slightly lower, which may be due to the participation of a small part of quartz and mullite in the geological polymerization reaction. In addition, the "steamed bun-shaped" peak $\left(2 \theta=20^{\circ} \sim 30^{\circ}\right.$ ), which reflects the characteristics of amorphous aluminosilicate in fly ash, gradually decreases and gradually moves to the right. The continuous low dispersion peak gradually becomes obvious, which shows that the formation of amorphous gel phase and gradually increase with age.

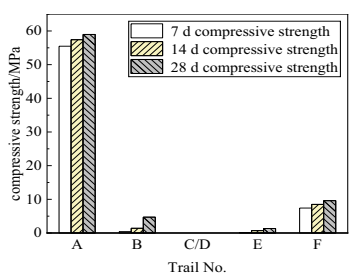

Figure 1. compressive strength of geopolymer at different curing periods.

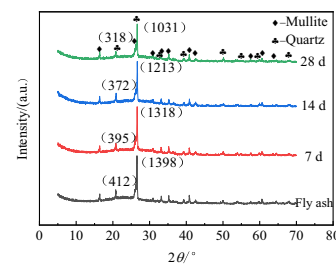

Figure 2. XRD pattern of fly ash based geopolymer olymer.

Figure 3 is the XRD pattern of fine-grained geopolymers under different curing ages. It can be concluded that the XRD patterns of fine-grained raw materials are basically similar to those of samples prepared at different ages, and the main crystal phases are quartz and kaolinite. The characteristic that the intensity of the diffraction peak decreases with age is consistent with that of fly ash geopolymers, which can be attributed to the fact that the generated gel phase wraps the quartz crystals to weaken the detection intensity. The characteristic peaks of the original black stone in the raw materials gradually weakened and disappeared in the product. The black pillarite is a hydrous silicate mineral containing calcium and iron. The disappearance of its characteristic peak can be inferred that the black pillarite crystal is dissolved under alkaline conditions to form a gel material. Meanwhile, compared with those of the raw materials and the $7 \mathrm{~d}$ and $14 \mathrm{~d}$ geopolymers, the XRD pattern of the $28 \mathrm{~d}$-age samples showed a characteristic peak that was not detected by the samples at the previous age. The peak is the characteristic peak of the zeolite phase.

Figure 4 shows the XRD patterns of geopolymers prepared with fine particles and fly ash under different curing ages. Its main crystal phases are kaolinite, quartz and mullite, which are consistent with the main crystal structure of fly ash and fine particles. The diffraction intensity of its characteristic peaks varies with age and is similar to geopolymers prepared from fine particles of fly ash and granite residual soil, and their intensity gradually weakens with age. Within the range of $2 \theta=15^{\circ} \sim 35^{\circ}$, the diffraction peaks can be observed, indicating the formation of an amorphous gel phase. 
With the increase of age, the dispersion peak and peak bag change slightly, indicating that the reaction has been basically completed at $7 \mathrm{~d}$ of age. Meanwhile, compared with the XRD patterns of fine-grained geopolymers, no new characteristic peaks of crystal phase structure were found. It can be inferred that the co-reaction of fly ash can inhibit the formation of zeolite phase in fine-grained geopolymers.

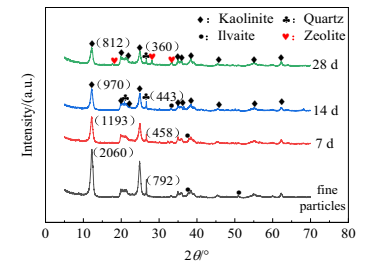

Figure 3. XRD pattern of granite residual soil based geopolymer.

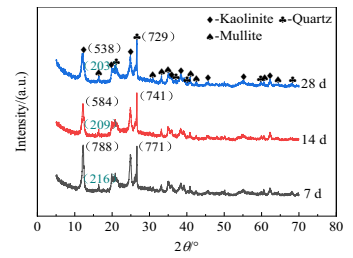

Figure 4. XRD pattern of composite materials based geopolymer.

\subsection{Microstructure Analysis of Geopolymers}

Figure 5 is a microstructure diagram of geopolymers prepared with fine particles and fly ash under different curing ages. With the increase of age, the number of pores in the sample gradually decreases, and the structure tends to be dense, which is consistent with the gradual increase of the strength of the sample with age. When the curing age is $7 \mathrm{~d}$, the spherical structure of fly ash has been destroyed and more gelling substances are formed in situ, and a small amount of gelling substances have also formed on the surface of the flake structure of soil particles. It shows that the raw material content of amorphous silicon-aluminum oxide in fly ash is significantly higher than that of fine particles, and the reaction speed is fast. It is the main source of the gelling material of geological polymerization products and makes a great contribution to the improvement of the overall strength of the sample. When the sample is cured for 14 days, the fly ash microbeads have been basically depolymerized and then polymerized to form a gelling substance, and more gelling substances are also formed on the surface of the soil particles. It shows that fly ash can improve the reactivity of the amorphous siliconaluminum oxide in the fine particles and accelerate the geological polymerization reaction in the fine particles. When the curing age reaches $28 \mathrm{~d}$, the flocculent gelling substance is gradually filling the gaps in the structure. It can be inferred that the addition of fly ash increases the total amount of $\mathrm{Si}$ and $\mathrm{Al}$ oligomers, so that the generated zeolite nuclei have fierce competition between oligomers and cannot crystallize and grow, inhibiting the phase transformation of amorphous gel zeolite .

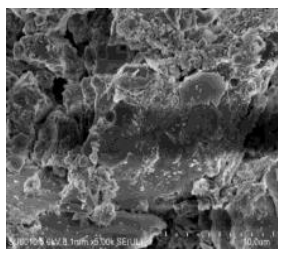

(a) $7 \mathrm{~d}$

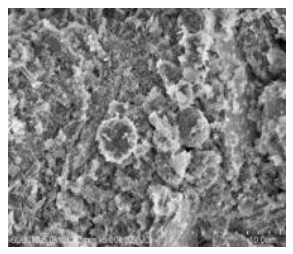

(b) $14 \mathrm{~d}$

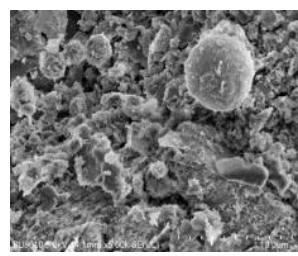

(c) $28 \mathrm{~d}$

Figure 5. SEM image of composite materials based geopolymer $(\times 5000)$. 


\section{Conclusion}

Through the study of different particle groups of fly ash and granite residual soil, as well as the geological polymerization reaction mechanism of granite residual soil and fly ash together. The conclusions reached are as follows:

- In the granite residual soil, only fine particles $(\mathrm{d} \leq 0.075 \mathrm{~mm})$ contain amorphous silicon-aluminum oxides, which can participate in geopolymerization to form geopolymers. The strength of fly ash geopolymers, granite residual soil fine-grained geopolymers, and fly ash + fine-grained composite materials are all increasing with age. The order of compressive strength is: fly ash geopolymer $>$ fly ash+fine-grained composite material prepared geopolymer $>$ granite residual soil fine-grained geopolymer.

- Through the study of fine-grained geopolymers of granite residual soil, it is concluded that the amorphous silicon-aluminum oxide content in the fine particles is low, and the reaction activity is low, which makes the final strength and early strength of the sample low. At the same time, the amount of $\mathrm{Si}$ and $\mathrm{Al}$ oligomers formed by the preliminary reaction of geological polymerization is small, and they are easy to be supersaturated to form nanozeolite crystal nuclei. The competition between crystal nuclei is small and fully developed. Zeolite crystals with large crystallinity are filled with samples. The effect is beneficial to enhance the integrity of the sample and improve the compressive strength of the sample.

- Through the study of geopolymers prepared from fly ash+fine particle composite materials, it is concluded that fly ash can increase the reactivity of amorphous silicon aluminum oxide in fine particles and accelerate the rate of geological polymerization. At the same time, fly ash will inhibit the zeolite phase transformation of the amorphous cementitious material. However, due to the low content of amorphous silicon-aluminum oxide in the fine particles, the quality of the resulting gelled material will not increase due to the increase in reactivity. The main gelling material is provided by fly ash, which leads to the gelled material obtained by the reaction of the entire sample. The amount is small and the intensity is low.

\section{References}

[1] Feng ZY, Luo X and Huang QL. Study on the comprehensive utilization of residual soil resources. 2018 Feb; 34(02): 69-71.

[2] Mclellan BC, Williams RP and Lay J. Costs and carbon emissions for geopolymer pastes in comparison to ordinary portland cement. $2011 \mathrm{Feb} ; 19(9-10)$ : 1080-1090.

[3] Pacheco-Torgal F, Castro-Gomes J and Jalali S. Investigations about the effect of aggregates on strength and microstructure of geopolymeric mine waste mud binders. 2007 Feb; 37(6): 933-941.

[4] Mao MJ, Ren JY and Zhang WB. Study on the mechanical properties of fly ash geopolymer concrete. 2016 May; (05): 78-80.

[5] Lv QF, He JF, Wang ZS. Study on the interaction mechanism between clay minerals and alkali activated geopolymers. $2020 \mathrm{Dec} ; 28(06)$ : 1205-1212.

[6] Wang HL, Zhao YB and Rong H. Influence of the muck content on mechanical properties of fly ash geopolymer. $2019 \mathrm{Feb}$; 38(02): 140-144. 